\title{
Predicting the hardness and solute distribution during brazing of Ti-6Al-4V with TiZrCuNi filler metals
}

\author{
E.I. Galindo-Nava ${ }^{a}$, Y.J. Jing ${ }^{b, c}$, J. Jiang $^{c}$ \\ ${ }^{a}$ Department of Materials Science and Metallurgy, University of Cambridge \\ 27 Charles Babbage Rd, Cambridge, CB3 0FS, UK \\ email: eg375@cam.ac.uk, +44 1223334300 \\ ${ }^{b}$ Aeronautical Key Laboratory for Welding and Joining Technology Beijing 1000024, PR China \\ ${ }^{c}$ Department of Mechanical Engineering, Imperial College London \\ Exhibition Road, London, SW7 2AZ, UK
}

\begin{abstract}
A modelling approach for the hardness and solute distribution during brazing of Ti-6Al-4V with Ti-Zr-Cu-Ni amorphous fillers is presented. The model for hardness incorporates main strengthening mechanisms in $\alpha+\beta$ alloys and a solid-state diffusion model is employed to describe redistribution of $\mathrm{Zr}, \mathrm{Cu}$ and $\mathrm{Ni}$ in the joints.
\end{abstract}

Keywords: A. modeling; A. electron microscopy; A. hardness; B. titanium alloys; brazing Brazing is a promising technology for joining Ti-based alloys, as this process has less impact on mechanical properties of joint components $[1,2]$. $\mathrm{Ti}-\mathrm{Zr}-\mathrm{Cu}-\mathrm{Ni}$ brazing filler metals have been designed to provide better strength and corrosion resistance compared to other fillers [3-5]. However, a number challenges still exist when optimising filler alloying and process design. When joining Ti-6Al-4V (wt\%), improving the strength of the fillers requires brazing at temperatures close to the $\beta$ transformation temperature $\left(T_{\beta}=980\right.$ $\left.{ }^{\circ} \mathrm{C}\right)$, which can affect the mechanical properties by coarsening the $\alpha+\beta$ microstructure [6]. In contrast, if the brazing temperature is too low or if there is not enough time to allow complete solidification of the filler, the strength and ductility of the $\mathrm{Ti}-\mathrm{Zr}-\mathrm{Cu}-\mathrm{Ni}$ brazed joints is reduced by the presence of brittle and hard intermetallics, such as $\mathrm{Zr}_{2} \mathrm{Cu}, \mathrm{Ti}_{2} \mathrm{Cu}$ and $(\mathrm{Ti}, \mathrm{Zr})_{2} \mathrm{Ni}[4,5,7]$. Although several experimental studies have been carried out to optimise the composition of the fillers and brazing parameters $[3,8,9]$, the strengthening mechanisms of the joints have not been described in detail, therefore limiting scope for further development of brazing fillers with higher strength. 
In this work a modelling approach is introduced to predict the hardness of Ti alloys and elemental distribution occurring during brazing, allowing us to understand the mechanisms controlling the variation in the strength of brazed joints. First, an experimental study of the mechanical properties and elemental distribution in brazed joints is presented. Second, a model accounting for main strengthening mechanisms in $\alpha+\beta$ alloys is introduced. In addition, a model for elemental diffusion during brazing is introduced to compare the diffusion efficiency of different fillers. The approach is applied to develop a strategy for alloy and process design to optimise the strength of brazed joints with different Zr additions.

A Ti-6Al-4V alloy plate of $100 \mathrm{~mm}$ thickness was used as the base material. Tensile tests samples were cut at the centre and three brazing fillers were employed to study the role of chemical composition, specifically Zr additions, in the strength of the joints. The compositions of the fillers and processing procedures are shown in Table 1. The average initial width of the fillers, $R_{0}$, was measured to be $\sim 40 \mu \mathrm{m}$ in all cases. Vacuum brazing was performed in a vacuum chamber of $5 \times 10^{-5}$ mbar. The fillers were measured to have a narrow melting temperature range of $830-890{ }^{\circ} \mathrm{C}$ making them suitable for brazing $[3,4]$. Previous work showed that the designed brazing conditions in Table 1 are appropriate to avoid Ti-Cu and Ti-Ni intermetallics [5,10,11]. Mechanical tests at room temperature including tension and microhardness were carried out to evaluate the mechanical properties of the joints. The tensile tests were carried out using a MTS tester at a constant speed of $0.1 \mathrm{~mm} / \mathrm{min}$. Standard metallographic preparations such as grinding and polishing were conducted. The samples were finally etched by Kroll's reagent $\left(3 \mathrm{ml} \mathrm{HF}+6 \mathrm{ml} \mathrm{HNO}_{3}+100 \mathrm{mlH}_{2} \mathrm{O}\right)$ to reveal the microstructures in SEM (JEOL JXA 8200). Compositional analysis and elemental distribution were evaluated by using energy dispersive X-ray spectroscopy (EDS). Further details about experimental procedures can be found in $[5,10,11]$. 
Table 1: Chemical composition of the filler metals and their brazing process.

\begin{tabular}{cccc}
\hline Filler & Composition (wt\%) & Melting pont $\left({ }^{\circ} \mathrm{C}\right)$ & Brazing process \\
\hline $37.5 \mathrm{Zr}$ & Ti-37.5Zr-15Cu-10Ni & $830-840$ & $930^{\circ} \mathrm{C} / 3600 \mathrm{~s}$ \\
$18 \mathrm{Zr}$ & $\mathrm{Ti}-18 \mathrm{Zr}-15 \mathrm{Cu}-10 \mathrm{Ni}$ & $840-860$ & $930^{\circ} \mathrm{C} / 3600 \mathrm{~s}$ \\
$10 \mathrm{Zr}$ & $\mathrm{Ti}-10 \mathrm{Zr}-15 \mathrm{Cu}-10 \mathrm{Ni}$ & $880-890$ & $930^{\circ} \mathrm{C} / 3600 \mathrm{~s}$ \\
\hline
\end{tabular}

Figure 1 shows SEM backscattered electron images of the brazed fillers and matrix in (a) $37.5 \mathrm{Zr}$, (b) 18Zr and (c) 10Zr. Widmanstätten microstructure was found throughout the entire joint section due to an eutectoid reaction (the bright areas represent $\beta$ phase) [6]. No voids or cracks were found along the joints and no intermetallic compounds were observed in any condition. The volume fraction of $\alpha, V_{\alpha}$, in the matrix is approximately $80 \% \pm 5 \%$, whereas $V_{\alpha}$ in the joints ranges between $60-70 \%$; the decrease in $\alpha$ volume fraction is due to $\mathrm{Ni}$ and $\mathrm{Cu}$ additions ( $\beta$-stabilisers) lower the temperature of the $\alpha+\beta$ phase field [2]. The $\alpha$ size, $d_{\alpha}$, in the matrix is approximately $20 \mu \mathrm{m}$, whereas the thickness of the $\alpha$ laths in the joints is $5-10 \mu \mathrm{m}$; a low fraction of coarse laths $\left(d_{\alpha} \approx 15\right.$ $\mu \mathrm{m})$ is also present in Filler 37.5Zr. The joint thickness, $R_{l}$, decreases with increasing $\mathrm{Zr}$ content: $R_{l}=190 \pm 15 \mu \mathrm{m}, 215 \pm 15 \mu \mathrm{m}$ and $250 \pm 30 \mu \mathrm{m}$ in fillers $37.5 \mathrm{Zr}, 18 \mathrm{Zr}$ and $10 \mathrm{Zr}$, respectively. Possible explanations why $\mathrm{Zr}$ and not Ti mainly influences $R_{l}$ are that Zr dictates the melting point of this family of fillers [3] and it has the lowest diffusivity, decreasing the growth of the interfaces by interdiffusion between the filler and matrix. Other authors have found similar results. For instance, Ganjeh et al. [8] found that a filler containing $66 \mathrm{Zr}$ wt\% produced similar brazing performance at $990{ }^{\circ} \mathrm{C}$ than a filler with $27 \mathrm{Zr}$ wt\% brazed at a lower temperature of $950{ }^{\circ} \mathrm{C}$. Table 2 shows the solid-state diffusion parameters of $\mathrm{Zr}, \mathrm{Cu}$ and $\mathrm{Ni}$ in Ti obtained from [7], showing the lower diffusivity of $\mathrm{Zr}$ at $930{ }^{\circ} \mathrm{C}$. Additional results reporting detailed microstructural characterisation at higher magnification for all materials can be found in $[10,11]$. 

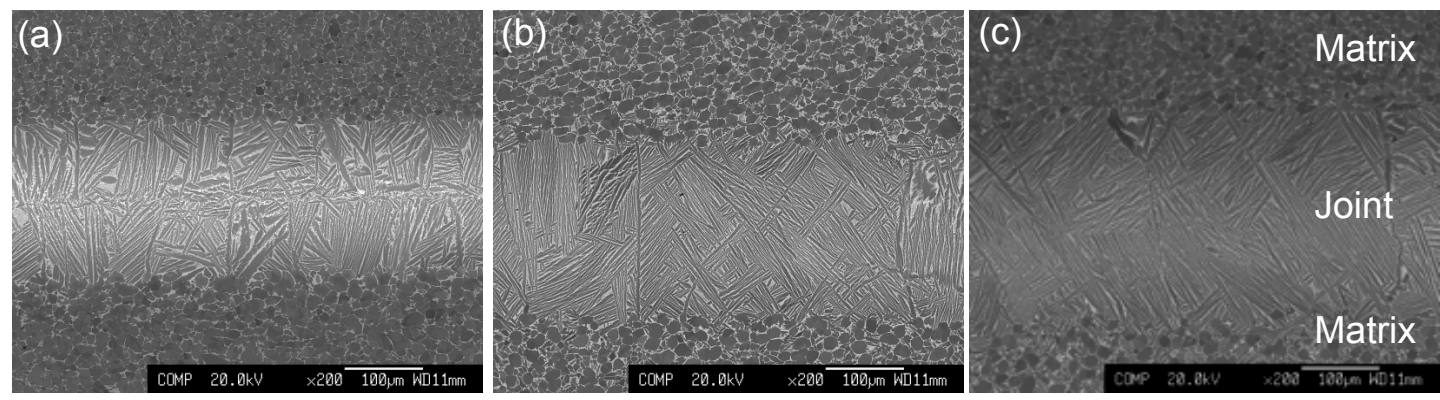

Figure 1: Microstructures at the joint and interfaces in (a) 37.5Zr, (b) 18Zr and (c) 10Zr.

Table 2: Diffusion and solid solution strengthening parameters of $\mathrm{Zr}, \mathrm{Cu}$ and $\mathrm{Ni}$.

\begin{tabular}{ccccc}
\hline Element & $D_{0}\left(\mathrm{~m}^{2} / \mathrm{s}\right)$ & $Q(\mathrm{~kJ} / \mathrm{mol})$ & $D$ at $930{ }^{\circ} \mathrm{C}\left(\mathrm{m}^{2} / \mathrm{s}\right)$ & $B_{i}(\mathrm{MPa} / \mathrm{at})$ \\
\hline $\mathrm{Zr}$ & $4.7 \times 10^{-7}$ & 148 & $1.7 \times 10^{-13}$ & 983 \\
$\mathrm{Cu}$ & $2.1 \times 10^{-7}$ & 122 & $10^{-12}$ & 1779 \\
$\mathrm{Ni}$ & $1.7 \times 10^{-6}$ & 132 & $3.1 \times 10^{-12}$ & 2762 \\
\hline
\end{tabular}

Microhardness measurements at the centre of the joint $(0 \mu \mathrm{m})$ and matrix $( \pm 150$ $\mu \mathrm{m})$ are shown in Figure 2. Between 4 and 5 measurements were performed for each condition to ensure that the results are statistically relevant; this is due to the difficulty of performing an array of microhardness measurement across the joints, as they are only 100-200 $\mu \mathrm{m}$ in thickness and the indentations are $\sim 50 \mu \mathrm{m}$. The (blue) circles, (red) squares, and (green) triangles represent the hardness in Fillers 37.5Zr, 18Zr, and 10Zr, respectively, whereas the (black) rhomboids represent measurements of the matrix. The shadowed area indicates the initial width of the fillers, whereas the dotted lines indicate the average thickness of the joints $\left(R_{l}\right)$. The hardness in the matrix is $3041 \mathrm{MPa}$. The average microhardness at the centre of fillers $37.5 \mathrm{Zr}, 18 \mathrm{Zr}$ and $10 \mathrm{Zr}$ is $3992 \mathrm{MPa}, 3521$ $\mathrm{MPa}$ and $3463 \mathrm{MPa}$, respectively, and all values of $37.5 \mathrm{Zr}$ lie above those for other fillers. As for the tensile tests, the average ultimate tensile strength (UTS) of fillers 37.5, 18Zr and $10 \mathrm{Zr}$ was measured to be $917 \mathrm{MPa}, 894 \mathrm{MPa}$ and $876 \mathrm{MPa}$, respectively. The tensile elongation ranged between $12 \%$ and $19 \%$ in all cases; the samples using fillers $37.5 \mathrm{Zr}$ and $10 \mathrm{Zr}$ failed at the joints, whereas the samples with filler $18 \mathrm{Zr}$ failed at the matrix. Additional information of the tensile tests can be found in $[10,11]$. The UTS results 
have good correlation with the hardness measurements, indicating that the strength of the joints increases with $\mathrm{Zr}$ content at the centre of the fillers. Therefore, the hardness at the joints is considered partial indicator of the effective strength of the brazing joints [3]. The higher strength of the joints is attributed to the solid solution strengthening of $\mathrm{Zr}$, as the $\alpha+\beta$ microstructure is approximately constant and no intermetallics were detected (Figure 1).

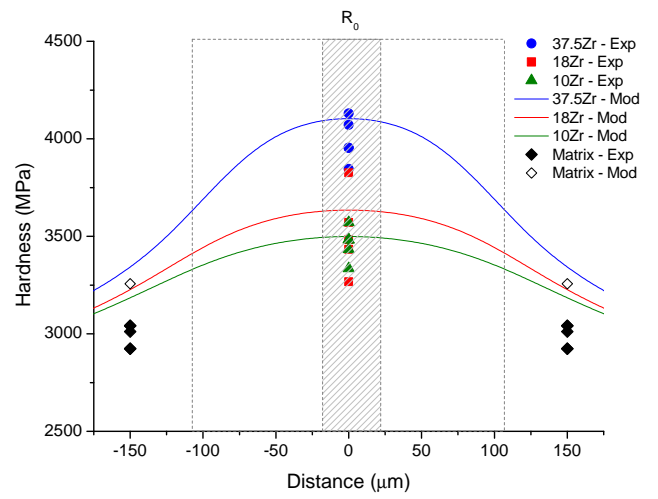

Figure 2: Experimental (dots) and modelled (lines) Hardness profiles of the brazed joints and matrix in fillers 37.5Zr (blue), 18Zr (red), and 10Zr (green); the black and white rhomboids represent experimental and modelled $H_{v}$ in the matrix, respectively.

Figure 3(a) shows the chemical distribution measured by EDS at the centre of the joints $(0 \mu \mathrm{m})$, diffusion interface $\left(R_{l}\right)$ and matrix $( \pm 150 \mu \mathrm{m})$. The distribution of $\mathrm{Zr}, \mathrm{Cu}$ and $\mathrm{Ni}$ is different across the joints due their different diffusion rates (Table 2). In all cases, the distribution of $\mathrm{Cu}$ and $\mathrm{Ni}$ at the centre of the joints remains relatively constant in the range 4-6 wt\% and 2.5-4 wt\%, respectively; these values decrease steadily at the interface, although with some scatter. The $\mathrm{Cu}$ and $\mathrm{Ni}$ contents in the matrix are very low $(0.5-1 \mathrm{wt} \%)$ in all cases, however the concentration of $\mathrm{Cu}$ in $18 \mathrm{Zr}$ is $\sim 3 \mathrm{wt} \%$. The variations can be due to inhomogeneities during brazing [5]. The Zr content at the centre of the joints increases with increasing the nominal concentration of the filler and the overall concentration of Zr decreases steadily. This suggests that the increase of Zr in the fillers can be responsible for the increase in hardness of the joints. 
(a)

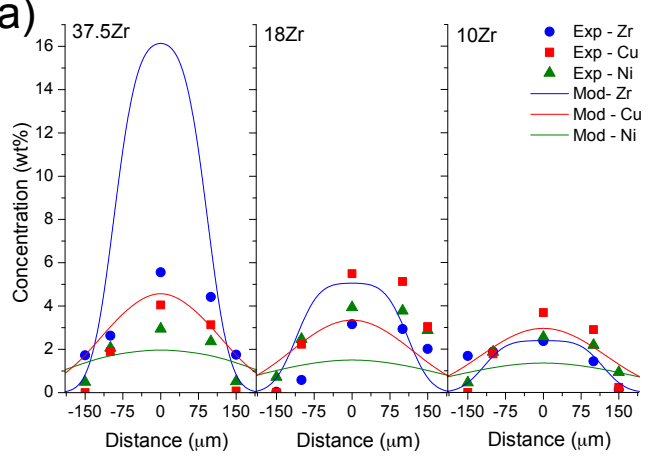

(b)

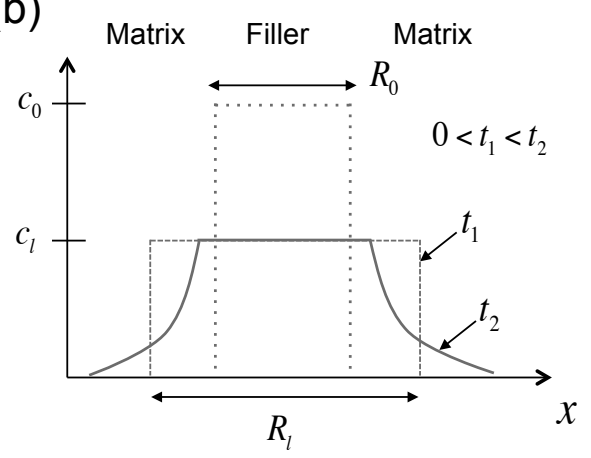

Figure 3: (a) Experimental (dots) and modelled (lines) concentration profiles of Zr (blue), $\mathrm{Cu}$ (red), and $\mathrm{Ni}$ (green) in brazed joints using fillers $37.5 \mathrm{Zr}$ (left), $18 \mathrm{Zr}$ (centre) and 10Zr (right). (b) Schematic representation of elemental diffusion during brazing.

Variations in the microstructure and chemical composition control the hardness at different locations of the brazed joints. The strength (and consequently the hardness) of Ti alloys with no intermetallics stems from the following $[1,12]$ : 1) solid solution in the $\alpha$ and $\beta, 2)$ the relative $\alpha+\beta$ volume fraction and 3) grain boundary strengthening. Solid solution strengthening has an important role due to the distribution of $\mathrm{Zr}, \mathrm{Cu}$ and $\mathrm{Ni}$ in the joints. $\mathrm{Cu}$ and $\mathrm{Ni}$ are $\beta$-partitioning elements [2], however an overall solid solution contribution of all elements in $\left(\alpha^{-}\right) \mathrm{Ti}$ is assumed due to the lack of systematic reports on solid solution hardening in $\beta$-Ti alloys. The solid solution strengthening term, $\sigma_{s s}$, is defined using the multicomponent formula from Labusch [13]: $\sigma_{s s}=\left(\sum_{i} B_{i}^{3 / 2} x_{i}\right)^{2 / 3}$, where $x_{i}$ is the atomic concentration of element $i$ and $B_{i}$ is the solid solution strengthening constant [14]: $B_{i}=\kappa \mu\left(\eta_{i}^{\prime}+16 \delta_{i}\right)^{3 / 2}$, where $\kappa$ is a constant and $\eta_{i}^{\prime}=\left|\eta_{i}\right| /\left(1+0.5 \eta_{i}\right)$; $\eta_{i}=\frac{\mu_{i}-\mu_{T i}}{\mu_{T i}}$ and $\delta_{i}=\frac{r_{i}^{a}-r_{T i}^{a}}{r_{T i}^{a}}$ are the local modulus change and lattice strain of element $i$ in $\mathrm{Ti}$, respectively; and $\mu_{i}$ and $r_{i}^{a}$ are the shear modulus and atomic radius of element $i$, respectively; these parameters were obtained from [15]. $\kappa=0.0082$ was determined using the experimental data in Ti-Zr alloys reported in $[16,17]$. Table 2 shows $B_{i}$ for $\mathrm{Zr}, \mathrm{Cu}$ and Ni. In addition, $B_{A l}=1813 \mathrm{MPa} /$ at and $B_{V}=126 \mathrm{MPa} /$ at were determined for the matrix. A Hall-Petch constant of $579 \mathrm{MPa} \mu \mathrm{m}^{1 / 2}$ for $\alpha$ grain-boundary strengthening is obtained from $[18]^{*}$. The grain-boundary contribution of $\beta, \sigma_{\beta}$, is considered fixed and

\footnotetext{
${ }^{*}$ This value is obtained by multiplying the reported Hall-Petch constant of the resolved shear stress
} 
equal to $[2,20,21]$ : $1350 \mathrm{MPa}$, due to the complexity in isolating size and morphology effects in the strength of Ti-6Al-4V.

The hardness is known to be proportional to the yield strength, however the proportionality constant varies with alloying system [22]. Keist and Palmer [23] obtained a relationship between the yield strength and microhardness in additively manufactured Ti-6Al-4V: $H_{v}(\mathrm{MPa})=3.6\left(\sigma_{Y}(\mathrm{MPa})+90\right)$. This equation is assumed valid in the present case, as the microstructure of additively manufactured $\alpha+\beta$ alloys and brazed joints is very similar (Widmanstätten structure). Combining the previous results, the Hardness is expressed as [12]:

$$
H_{v}(\mathrm{MPa})=3.6\left(\sigma_{Y}+90\right)=3.6\left(\sigma_{s s}+\frac{579}{\sqrt{d_{\alpha}}} V_{\alpha}+\sigma_{\beta}\left(1-V_{\alpha}\right)+90\right)
$$

This equation shows that the hardness of the joints depends on their local composition $\left(\right.$ via $\left.\sigma_{s s}\right)$ and $\alpha+\beta$ microstructure. The latter is approximately constant when modifying the composition of the filler (Figure 1) and $H_{v}$ can be predicted for different fillers/brazing conditions if the $\mathrm{Zr}, \mathrm{Cu}$ and $\mathrm{Ni}$ distribution is known.

Relevant steps involved in the diffusion of a brazed joint have to be considered in order to predict solute redistribution. The main steps of this process are shown schematically in Figure 3(b) [1]: 1) at $t=0$ the filler metal with initial thickness, $R_{0}$, melts and starts dissolving into the base metal as a consequence of heating the sample above its melting point and subsequent elemental diffusion; 2) the liquid layer widens reaching a maximum thickness of $R_{l}$ and isothermal solidification starts at $t=t_{1}$; this is due to an increase of the solidus temperature in the vicinity of the solid-liquid interface; 3) solid-state diffusion continues within the joint and the liquid layer shrinks to complete the solidification process $\left(t=t_{2}\right) ; R_{l}$ also increases. Assuming mass conservation between steps 1 and 2 , the concentration of the joint when isothermal solidification starts, $c_{l}$, is expressed in terms of $R_{0}, R_{l}$ and the initial concentration of the filler, $c_{0},[7,24]: c_{0} R_{0}=c_{l} R_{l}$, giving $c_{l, i}=c_{0, i} \frac{R_{0}}{R_{l}}$, where $i=\mathrm{Zr}, \mathrm{Cu}$ and Ni. Following Fick's second law, a number of authors have shown that the maximum joint thickness can be expressed as $[24,25]: R_{l}=R_{0}+k_{l} \sqrt{D_{l} t_{l}}$, where $D_{l}$ times the Taylor factor for compression, $M=3[19]$, to obtain an axial Hall-Petch stress. 
is the effective diffusion coefficient, $t_{l}$ is the time for starting isothermal solidification and $k_{l}$ is a fitting constant for specific alloys. In practice, it is difficult to determine the effects of liquid formation during heating and subsequent solid-state diffusion, controlling the growth of $R_{l}$ after $t_{l}$ has been reached [7]. This is due to microstructural characterisation and elemental distributions can only be done after the brazing process is finished, therefore it is complicated to estimate $t_{l}$ experimentally. Nevertheless, several authors have argued that the melting process and subsequent solidification follow the same diffusion trends than those for solid-state elemental distribution, and these effects can be included in $k_{l}[7,24,25]$; therefore, the total brazing time $t$ is considered instead of $t_{l}$ with $D_{l}=D_{Z r}$, to simplify the calculations, as we are concerned with brazing conditions where complete solidification occurs; implications of considering incomplete solidification are discussed later in the text. In the present case, it was shown that the Zr content is responsible for $R_{l}$ variations in the fillers tested and $k_{l}$ is estimated using the experimental values of $R_{l}$ with different $\mathrm{Zr}$ additions. An empirical formula is obtained as a function of the initial Zr content in the filler and brazing time: $R_{l}=R_{0}+(8.6-0.08 \mathrm{Zr}(\mathrm{wt} \%)) \sqrt{D_{Z r} t}[\mathrm{~m}]$. The formula proposed in this work is compared against additional experimental measurements from the literature to show the validity of the previous assumptions. Matsu et al. [7] measured $R_{l}=75 \pm 10 \mu \mathrm{m}$ after brazing commercially pure titanium with Ti-37.5Zr$15 \mathrm{Cu}-10 \mathrm{Ni}\left(\mathrm{wt} \%\right.$ ) at $880{ }^{\circ} \mathrm{C}$ for $10 \mathrm{~min}$, whereas our equation predicts $R_{l}=81 \mu \mathrm{m}$ for the same conditions. Similarly, Ganjeh et al. [8] measured $R_{l}=102 \pm 10 \mu \mathrm{m}$ and $130 \pm 30$ $\mu \mathrm{m}$ in a Ti-6Al-4V joint with filler composition Ti-27Zr-14Cu-13Ni (wt\%) after brazing at $950{ }^{\circ} \mathrm{C}$ for $10 \mathrm{~min}$ and $30 \mathrm{~min}$, respectively; our equation predicts $R_{l} 115 \mu \mathrm{m}$ and 169 $\mu \mathrm{m}$ for same conditions, respectively.

Elemental diffusion in the solidification front (step 3) is described by a standard diffusion equation $[7,24,25]$. It is assumed that one-dimensional diffusion occurs on the horizontal direction $x$, as schematically shown in Figure 3(b). Symmetry is assumed and $x=0$ is taken at the centre of the filler. The evolution of the solute concentration in the filler, $c_{i}$, is given by: $\frac{\partial c_{i}}{\partial t}=D_{i} \nabla^{2} c_{i}$, where $D_{i}$ is the diffusion coefficient of $i=\mathrm{Zr}, \mathrm{Cu}, \mathrm{Ni}$ in the solid state. Ti diffusion from and to the joint is assumed to be determined by the diffu- 
sion profiles of other elements to warranty mass conservation, i.e. $\mathrm{Ti}+\mathrm{Zr}+\mathrm{Cu}+\mathrm{Ni}=100 \%$ in all locations of the joint; no $\mathrm{Al}$ or $\mathrm{V}$ diffusion is considered to simplify the calculations. Each element has initial concentration density $c_{i}=c_{l, i}$ in $|x| \leq \frac{R_{l}}{2}$ and $c_{i}=0$ outside this range. The boundary conditions are set by mass conservation criteria $[24,25]$. The solution of this problem is given by [26]:

$$
\begin{aligned}
& c_{Z r}=\frac{c_{l, Z r}}{2}\left(\operatorname{erfc}\left(\frac{x+\frac{R_{l}}{2}}{2 \sqrt{D_{Z r} t}}\right)-\operatorname{erfc}\left(\frac{x-\frac{R_{l}}{2}}{2 \sqrt{D_{Z r} t}}\right)\right) \\
& c_{C u}=\frac{c_{l, C u}}{2}\left(\operatorname{erfc}\left(\frac{x+\frac{R_{l}}{2}}{2 \sqrt{D_{C u} t}}\right)-\operatorname{erfc}\left(\frac{x-\frac{R_{l}}{2}}{2 \sqrt{D_{C u} t}}\right)\right) \\
& c_{N i}=\frac{c_{l, N i}}{2}\left(\operatorname{erfc}\left(\frac{x+\frac{R_{l}}{2}}{2 \sqrt{D_{N i} t}}\right)-\operatorname{erfc}\left(\frac{x-\frac{R_{l}}{2}}{2 \sqrt{D_{N i} t}}\right)\right)
\end{aligned}
$$

The combined models for diffusion and hardness are tested against experiments. Figure 2 shows the hardness predictions in fillers (blue) 37.5Zr, (red) 18Zr and (green) 10Zr using the predicted concentration profiles shown in Figure $3(\mathrm{a})$ (solid lines); $V_{\alpha}=65 \%$ and $d_{\alpha}=5 \mu \mathrm{m}$ were considered fixed in the joints (Figure 1). The hardness results show very good agreement in all cases suggesting that solid solution hardening of Zr causes the increase in tensile strength when no intermetallics are present. Additional predictions of the matrix (white rhomboids) are also plotted, showing very good agreement with the experiments; $d_{\alpha}=20 \mu \mathrm{m}, V_{\alpha}=80 \%$, and solid solution effects of $\mathrm{Al}$ and $\mathrm{V}$ are employed in this case. It is not possible to link the predictions of the matrix and joints due to sharp variations in the microstructure (not considered in the model), but it is interesting observing that the predictions with both microstructures lie within the same order of magnitude in the matrix region $( \pm 150 \mu \mathrm{m})$. As for the diffusion profiles, the models also show good agreement, except in $37.5 \mathrm{Zr}$ where the model predicts higher $\mathrm{Zr}$ at the centre of the joint. The discrepancy can be due to inhomogeneities in the diffusion profiles during chemical mapping. In previous work using the brazing conditions $900{ }^{\circ} \mathrm{C} / 30$ min in the same fillers [10], the Zr content at the centre of the joints in $37.5 \mathrm{Zr}$ and $18 \mathrm{Zr}$ was measured to be 18 wt $\%$ and 10.3 wt\%, respectively. These values contrast with the present results, as lower concentrations were measured. The higher $\mathrm{Zr}$ content is also consistent with the hardness measured to be as high as $4120 \mathrm{MPa}$ in filler 37.5Zr. In ad- 
dition, other authors have obtained similar Zr concentration profiles in high-Zr containing fillers. Matsu et al. [7] measured the Zr content in the joint to be $\sim 22.9$ wt\% after brazing commercially-pure titanium with Ti-37.5Zr-15Cu-10Ni (wt\%) at $880{ }^{\circ} \mathrm{C}$ for $60 \mathrm{~min}$; the predicted concentration of $\mathrm{Zr}$ at the centre of the joint using equation 2 under similar conditions is 19.2 wt\%. Ganjeh and Sarkhosh [9] studied the chemistry distribution of a joint with filler composition Ti-27Zr-14Cu-13Ni wt\% and brazing conditions $950{ }^{\circ} \mathrm{C}$ for 30 minutes. They reported Zr concentrations at the centre of the joints of $\sim 7 \mathrm{wt} \%$, whereas the model predicts $10.9 \mathrm{wt} \%$ under the same conditions. This analysis indicates that the predictions are consistent with other results having similar filler/brazing conditions.

The approximation can be employed to explore designing new brazing joints with improved properties. High Zr additions in the filler aid in improving the strength of the joints, however it also slows down the solidification kinetics. Brittle intermetallics can form as a consequence of incomplete solidification, affecting severely the strength of brazed joints $[4,7,8]$. It is interesting to explore how $\mathrm{Zr}$ affects the conditions for high strength whilst avoiding the presence of intermetallics. A number of experimental results relating the tensile strength of brazed joints and the approximate Zr concentration at the centre of the joints $\left(c_{Z r}\right)$ are shown in Figure $4(\mathrm{a})$; these results were collected from the literature. For Zr concentrations greater or equal than $\sim 20 \mathrm{wt} \%$ the strength of samples decreases drastically, and below these values the strength is close or similar to the typical strength of Ti-6Al-4V (850-1100 MPa) $[2,3,5,6,8,12]^{\dagger}$ This transition can be rationalised by a balance between the presence of intermetallics due incomplete solidification (hence the high Zr content), and solid solution hardening increasing when the Zr content in the filler is high.

It is possible to assess how $\mathrm{Zr}$ additions and brazing time affect the strength in $\mathrm{Ti}-$ Zr-15Cu-10Ni fillers using the model. It is considered that the optimal strength range is possible when $c_{Z r} \leq 20 \mathrm{wt} \%$. In addition, it is necessary to estimate whether any fraction of liquid $f_{l i q}$ is left at the centre of the joint to avoid the formation of intermetallics by incomplete solidification. For this, $f_{l i q}$ at $930^{\circ} \mathrm{C}$ is estimated using the CALPHAD

\footnotetext{
$\dagger$ It is worth noting that in some cases the fracture happened in the matrix, therefore the joint strength is assumed to be at least as strong as the matrix.
} 
software Thermocalc, and the predicted composition is considered as the equilibrium concentration in every time step. The commercial database for Ti-based alloys TTTi3 is used for the calculations and a linear relationship between the nominal concentration at the joint and $f_{l i q}$ was fitted to simplify calculations (with correlation factor $R^{2}=0.91$ ): $f_{\text {liq }}=0.0142 \mathrm{Zr}($ wt $\%)+0.05 \mathrm{Cu}($ wt $\%)+0.05 \mathrm{Ni}($ wt $\%)-0.75$. It is possible to find the alloy and process combination necessary to avoid intermetallic formation $\left(f_{\text {liq }}=0\right)$ and warranty good tensile strength using the previous formula and equation 2. The initial thickness of the fillers is also assumed to be $40 \mu \mathrm{m}$ (Fig. 3). Figure 4(b) shows the conditions when $f_{l i q}=0$ (red dashed line) and $c_{Z r}=20 \mathrm{wt} \%$ (blue solid line) as a function of $\mathrm{Zr}$ and brazing time. Optimal solutions lie within the shadowed area, where $f_{l i q}<0$ and $c_{Z r}<20 \mathrm{wt} \%$. If it is aimed at reducing the brazing time whilst increasing the joint strength, an optimal filler with concentration $40 \mathrm{Zr}-15 \mathrm{Cu}-10 \mathrm{Ni}$ could give the highest strength and no intermetallic formation after just 6 minutes (intersection of red and blue lines); the predicted hardness at the centre of the joint is $5160 \mathrm{MPa}$. It is also interesting exploring how the predictions shown in Figure 4(b) change when modifying the initial thickness of the filler. Additional calculations with $R_{0}=30 \mu \mathrm{m}$ and $60 \mu \mathrm{m}$ have been performed to estimate the time to reach the highest strength and no intermetallic formation (intersection of $f_{l i q}=0$ and $c_{Z r}=20 \mathrm{wt} \%$ ) with different thicknesses. For $R_{0}=30 \mu \mathrm{m}$ the time to reach this optimal condition is 3.5 minutes, whereas for $R_{0}=60$ $\mu \mathrm{m}$ it is predicted that it takes 15 minutes to avoid intermetallic formation and reach the highest strength. The nominal concentration of Zr for achieving these optimal conditions is practically constant at $\approx 40 \mathrm{wt} \%$ in both cases (same with $R_{0}=40 \mu \mathrm{m}$ ). These results indicate that the initial thickness of the filler can also be used as a controlling parameter to avoid intermetallic formation, as it can affect significantly the variation in optimal brazing conditions. These results show that the model, in principle, can be applied to define a combined alloy and process design for high-strength filler metals. 
(a)

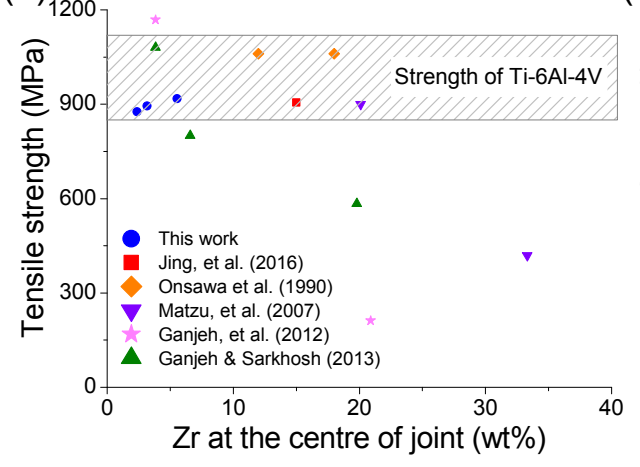

(b)

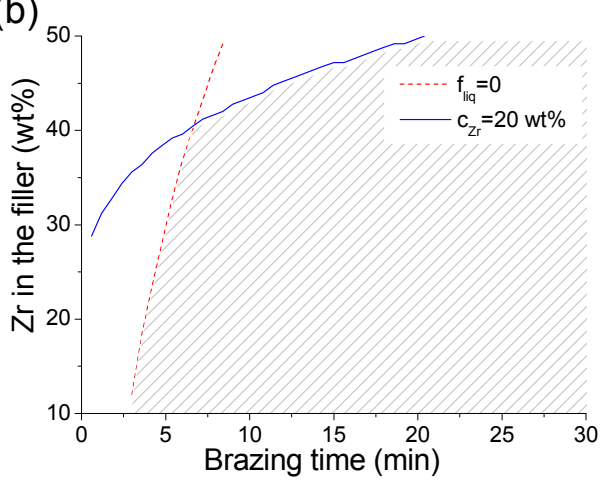

Figure 4: (a) Tensile strength variation after brazing Ti-6Al-4V vs Zr content at the centre of the joints. (b) Predicted effect of filler nominal composition in the brazing time to complete isothermal solidification and reach $20 \mathrm{wt} \% \mathrm{Zr}$ at the centre of the joint.

A modelling approach to predict the hardness and solute distribution during brazing of Ti-6Al-4V with $\mathrm{Ti}-\mathrm{Zr}-\mathrm{Cu}-\mathrm{Ni}$ fillers has been presented. Main strengthening mechanisms in $\alpha+\beta$ alloys were considered in the hardness predictions, including solid-solution, $\alpha / \beta$ fraction and Hall-Petch effects. A diffusion model was employed to describe the redistribution of $\mathrm{Zr}, \mathrm{Cu}$ and $\mathrm{Ni}$ during brazing leading to variations in the hardness at the joint. The agreement between the hardness measurements and predictions suggested that solid solution hardening due to Zr variations controls the local strength; however, detailed microstructural characterisation will be required to confirm this claim. Nevertheless, it was shown that the formulation can be applied to define a combined alloy and process design strategy for optimising the strength of brazed joints.

\section{Acknowledgements}

E.I. Galindo-Nava would like to acknowledge the Royal Academy of Engineering for his research fellowship funding and to Prof. Mark Blamire for the provision of laboratory facilities. In addition, significant support for Y.J. Jing and J. Jiang was received from the Chinese Scholarship Council of the Ministry of Education and the AVIC Centre for Structural Design and Manufacture at Imperial College London, which is funded by Aviation Industry Corporation of China (AVIC). 


\section{References}

[1] D. Jacobson, G. Humpston, Principles of Brazing, ASM International, 2005.

[2] M. Donachie, Titanium: a technical guide, ASM International, 2000.

[3] T. Ozawa, A. Suzumura, M. Ko, Brazing of titanium using low-melting-pint ti-based filler metals, Weld. J. 69 (1990) 462-467.

[4] A. Shapiro, Y. Flom, Brazing of titanium at temperatures below $800{ }^{\circ} \mathrm{C}$ : review and prospective application, Proc. 8th Int. Conf. Brazing.

[5] Y. Jing, X. Yue, X. Gao, D. Su, J. Hou, Influence of Zr content on the performance of TiZrCuNi brazing filler, Mater. Sci. Eng. A 678 (2016) 190-196.

[6] S. Banerjee, P. Mukhopadhyay, Phase transformations: Examples from titanium and zirconium alloys, Pergamon Materials Series, 2007.

[7] K. Matsu, Y. Miyazawa, Y. Nishi, T. Ariga, Brazing and interfacial reaction of commercially pure titanium with Ti-Zr-Based filler metals, Mater. Trans. 48 (2007) $1055-1059$.

[8] E. Ganjeh, H. Sarkhosh, M. Bajgholi, H. Khorsandi, M. Ghaffari, Increasing Ti-6Al$4 \mathrm{~V}$ brazed joint strength equal to the base metal by $\mathrm{Ti}$ and $\mathrm{Zr}$ amorphous filler alloy, Mater. Charac. 71 (2012) 31-40.

[9] E. Ganjeh, H. Sarkhosh, Microstructural, mechanical and fractographical study of titanium-CP and Ti-6Al-4V similar brazing with Ti-based filler, Mater. Sci. Eng. A 559 (2013) 119-129.

[10] Y. Jing, D. Su, X. Yue, T. Britton, J. Jiang, The development of high strength brazing technique for Ti-6Al-4V using TiZrCuNi amorphous filler, Materials Characterisation 131 (2017) 526-531.

[11] Y. Jing, X. Gao, D. Su, C. Zhao, J. Jiang, Increasing Zr content on the performance of Ti-Zr-Cu-Ni amorphous brazing fillers used on brazing Ti-6Al-4V, under review.

[12] B. Hayes, B. Martin, B. Welk, S. Kuhr, T. Ales, D. Brice, I. Ghamarian, A. Baker, C. Haden, D. Harlow, H. Fraser, P. Collins, Predicting tensile properties of Ti-6Al-4V produced via directed energy deposition, Acta Mater. 133 (2017) 120-133.

[13] R. Labusch, A statistical theory of solid solution hardening, Phys. Stat. Sol. 41 (1970) 659-669.

[14] E. Galindo-Nava, L. Connor, C. Rae, On the prediction of the yield stress of unimodal and multimodal $\gamma^{\prime}$ Nickel-base superalloys, Acta Mater. 98 (2015) 377-390.

[15] D. Lide, CRC Handbook of Chemistry and Physics, CRC Press, 2008.

[16] D. Williams, R. Wood, R. Jaffee, H. Ogden, The effects of zirconium in titanium-base alloys, J. Less-Common Metals 6 (1962) 219-225.

[17] A. Ingram, D. Williams, H. Ogden, Tensile properties of binary titanium-zirconium and titanium-hafnium alloys, J. Less-Common Metals 4 (1962) 217-225. 
[18] M. Zhang, J. Zhang, D. McDowell, Microstructure-based crystal plasticity modeling of cyclic deformation of Ti-6Al-4V, Int. J. Plas. 23 (2007) 1328-1348.

[19] E. Galindo-Nava, Modelling twinning evolution during plastic deformation in hexagonal close-packed metals, Mater. Des. 83 (2015) 327-343.

[20] J. Qazi, B. Marquardt, H. Rack, High-strength metastable beta-titanium alloys for biomedical applications, JOM 56 (2004) 49.

[21] A. Deveraj, V. Josjhi, A. Srivastava, S. Manandhar, V. Moxson, V. Duz, C. Lavender, A low-cost hierarchical nanostructured beta-titanium alloy with high strength, Nat. Comm. 11176.

[22] P. Zhang, S. Li, Z. Zhang, General relationship between strength and hardness, Mater. Sci. Eng. A 529 (2011) 62-73.

[23] J. Keist, T. Palmer, Development of strength-hardness relationships in additively manufactured titanium alloys, Mater. Sci. Eng. A 693 (2017) 214-224.

[24] S. Liu, D. Olson, G. Martin, G. Edwards, Modeling of brazing processes that use coatings and interlayers, Weld. J. 70 (1991) 207-215.

[25] H. Chen, J. Gong, S. Tu, Numerical modelling and experimental investigation of diffusion brazing SS304/BNi-2/SS304 joint, Sci. Tech. Weld. Join. 14 (2009) 32-41.

[26] J. Logan, Applied partial differential equations, Springer, 2015. 